\title{
LA MIGRACIÓN DE LOJANOS A ESPANA Y EL SUJETO MIGRANTE EN LA SEDUCCIÓN DE LOS SUDACAS
}

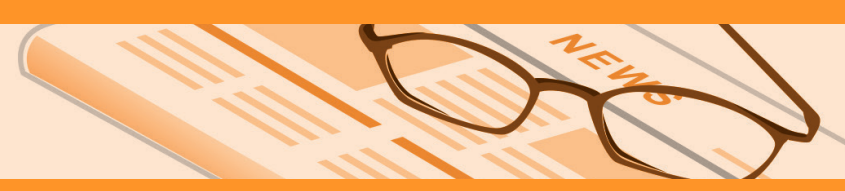

\section{Autor:}

Yovany Salazar Estrada ${ }^{1^{*}}$

${ }^{1}$ Universidad Nacional de Loja - Ecuador

Facultad de Filosofía, Letras y Ciencias de la Educación

"La correspondencia sobre este artículo debe dirigirse a Yovany Salazar Estrada, Carrera de Lengua Castellana y Literatura, Universidad

Nacional de Loja, Ciudad Universitaria "Guillermo Falconí Espinoza" (La Argelia). Teléf.: (593) 072547067 / (593) 072547234 / (593) 0725716 83 / E-Mail: ysalazarec2002@yahoo.es

Recibido: 2013-06-19 Aprobado: 2013-08-15 Publicado: $2013-12-18$

REVISTA DE INVESTIGACIÓN CIENTÍIFICA 


\section{Resumen}

Caracteriza el proceso migratorio de lojanos hacia España y los rasgos identitarios más sobresalientes del sujeto migrante representado en la novela La seducción de los sudacas de Carlos Carrión. Con el empleo de la metodología bibliográfico documental y la perspectiva sociológica de la crítica literaria se explicita la recreación literaria de la estampida migratoria de lojanos a España, a fines del Siglo XX y principios del XXI, en lo atinente a las causas, la salida, el viaje, la llegada y el asentamiento. Fundamenta, ejemplifica y analiza las principales características de la actual migración internacional de los ecuatorianos: cadenas y redes migratorias; cambio de destino migratorio desde Estados Unidos de Norteamérica a España; feminización del proceso migratorio; ocupaciones de los migrantes ecuatorianos en el sector secundario de la economía española; malos tratos a los inmigrantes "sin papeles", por parte de algunos españoles xenófobos. Los rasgos identitarios que singularizan al sujeto migrante representado en La seducción de los sudacas son la cosmovisión y la racionalidad comunitaria andina; la creencia religiosa católica; la crítica al sistema educativo de nivel superior; la memoria; el amor a la tierra nativa, la nostalgia y los recuerdos; el sentimiento de desarraigo; la paradoja de no estar conformes ni en el lugar de destino ni en el de origen; la paulatina pérdida de la autoestima y la dignidad humana; y, el carácter performativo. Se concluye que hay una representación del proceso migratorio y del sujeto migrante muy cercana a la realidad y a los estudios sociológicos de la problemática analizada.

Palabras clave: Carlos Carrión, La seducción de los sudacas, Migración Ecuador España, Migración internacional, Novela ecuatoriana, Novela lojana.

\section{Abstract}

This work It characterizes the migration process of Loja citizens to Spain and the most outstanding identity features of the migrant depicted in the novel The Seduction of Sudacas by Carlos Carrión. By using documentary and bibliographic methodology and sociological perspective of literary criticism, it explains the literary recreation of the migration stampede of Loja citizens to Spain, in the late twentieth century and early twenty-first, with regard to the causes, the output, travel, arrival and settlement. Fundamentally, it exemplifies and analyzes the main features of the current international migration of Ecuadorians migratory chains and networks; reassignment immigration from The United States of America to Spain, feminization of the migration process; occupations of Ecuadorian migrants in the secondary sector of the Spanish economy, mistreatment of "undocumented" immigrants, by some xenophobic spanish. The identity features which distinguish the migrant person represented in the seduction of sudacas are rational worldview and Andean Community; the Catholic religious belief, the critique of higher education system; memory; love of homeland, homesick and memories; the feeling of rootlessness, the paradox of not being conformed either at the place of destination or at the source; the gradual loss of self-esteem and human dignity, and the performative character. In conclusión, There is a representation of the migration process and the migrant person which is very close to the reality and sociological studies of the issues dealt with.

Key words: Carlos Carrion, Ecuadorian novel, International migration, “Lojana” novel, Narrative on migration, The seduction of sudacas. 


\section{Introducción}

De acuerdo con Salazar (2011), el problema de la migración, desde el campo a la ciudad, dentro y fuera de los linderos patrios de los estados nacionales, desde sus causas más remotas, fundamentales y contingentes, la salida, el viaje, la llegada, el asentamiento y las consecuencias ulteriores, ha sido recreado en algunas novelas emblemáticas del canon narrativo de nuestro continente. Unos pocos ejemplos de la novelística norteamericana, latinoamericana y del Ecuador bastarían para confirmar este aserto, el cual nos da la idea de que el problema de la migración siempre ha constituido un tema importante en la narrativa de ficción'.

A manera de ejemplo, como lo ejemplifica Salazar (2013), en la literatura ecuatoriana, la migración interna, campo ciudad, interregional e interprovincial, ha sido el referente central o al menos uno de los temas de fondo de cuatro novelas, que se han convertido en clásicos y obras de lectura obligatoria en nuestros sistema educativo nacional: Cumandá (1879) del polígrafo ambateño Juan León Mera (1832-1894), A la Costa (1904) del artista multifacético Luis Alfredo Martínez (1869-1909), El éxodo de Yangana (1949) del mejor cantor del chazo lojano y del habitante de la Región Sur del Ecuador, Ángel Felicísimo Rojas (1909-2003), y Los hijos (1962) del más conspicuo narrador de la ciudad de Cuenca de inicios del Siglo XX: Alfonso Cuesta y Cuesta (1912-1991)².

Conforme la afirmación del autor citado, el problema de la migración internacional de ecuatorianos, en dirección al Norte de mayor nivel de desarrollo, en variadas dimensiones, está presente desde El Muelle (1933) de Alfredo Pareja Diezcanseco (1908-1993), La Dama es una trampa(1989) de Galo Galarza Dávila (1956), El Inmigrante (2004) de Gonzalo Merino Pérez (1939).

${ }^{1}$ Cfr. Salazar Estrada, Yovany. (2011). La migración en las novelas El éxodo de Yangana de Ángel Felicísimo Rojas y La seducción de los sudacas de Carlos Carrión Figueroa. Tesis de Magíster en Filosofía en un mundo global presentada a la Universidad del País Vasco. San Sebastián. P. 13.

${ }^{2}$ Cfr. Salazar Estrada, Yovany. (2013).La migración en la novelística lojana. Loja: Casa de la Cultura Ecuatoriana "Benjamín Carrión”, Núcleo Provincial de Loja. Pp. 70-72, 74-76.
La memoria y los adioses (2006)de Juan Valdano Morejón (1940), El sudaca mojado (s.f.) de Mauricio Carrión Márquez, Los hijos de Daisy (2009) de Gonzalo Ortiz Crespo (1944) y Trashumantes en busca de otra vida(2012) de Stalin Alvear(1942)3.

Luego de la lectura de las novelas antes mencionadas, en esta ocasión, se optó por analizar la representación del proceso migratorio de lojanos a España y de los rasgos identitarios del sujeto migrante representado en la novela aún inédita La seducción de los sudacas $^{4}$, de Carlos Carrión Figueroa, de cuya lectura emergieron dos interrogantes, que permitieron delimitar los problemas específicos a ser investigados:¿De qué formas La seducción de los sudacas compendia, refleja y evidencia el proceso migratorio de lojanos a España? ¿Cuáles son los principales rasgos identitarios del sujeto migrante representado en La seducción de los sudacas?

El trabajo investigativo se justificó porque la novela estudiada recrea, literariamente, una problemática social que ha afectado, desde siempre, a todo el país y de manera particular a la provincia de Loja; un elevado porcentaje de cuyos habitantes, por causas naturales, sociales y sobre todo económicas, han emprendido un aventurado viaje en busca de la soñada "tierra de promisión”, en otros lugares del extranjero y con la esperanza de poder construir un futuro mejor, para sí mismos y para sus respectivas familias, fuera del solar nativo. Adicionalmente, la calidad estética con la que ha sido trabajada la obra de Carlos Carrión, la convierte en referente clave de la historia literaria del Ecuador y, más aún, con ella se consolida, con mucha fuerza, una nueva tendencia narrativa, como es la novela sobre la migración internacional.

En relación directa con los dos problemas específicos antes enunciados, la investigación se planteó cumplir dos objetivos específicos: 1) Caracterizar el proceso migratorio de lojanos a España, en La seducción de los sudacas y 2) Analizar las características del sujeto migrante, en La seducción de los sudacas.

${ }^{3}$ Cfr. Salazar Estrada, Yovany. (2013). Op. Cit. Pp. 73-74, 78-88.

${ }^{4}$ Carlos Carrión, La seducción de los sudacas, Loja: Inédito, 2010, 824p. 


\section{Metodología Utilizada}

En lo metodológico, para el desarrollo de la investigación se utilizó la metodología bibliográfico documental, recurriendo a dos tipos de fuentes de información: las primarias, que corresponden a la obra narrativa de Carlos Carrión, comenzando por la novela La seducción de los sudacas. Entre las fuentes secundarias figuran las obras de fundamentación teórico conceptual en torno a la migración internacional y la caracterización del sujeto migrante, los reportes de las investigaciones, monografías y tesis de grado y postgrado que, sobre el fenómeno de la migración, se han realizado en los últimos años, en el Ecuador y en España.

Para alcanzar el primer objetivo específico, luego de la lectura analítica, comprensiva y crítica de La seducción de los sudacas, que ha fundamentado la selección de las principales citas textuales que permitan trabajar las principales problemáticas del fenómeno migratorio; en un segundo momento se leyó las obras que abordan el proceso migratorio, en sus diferentes fases, para, en una tercera etapa, proceder a la ejemplificación y análisis de la representación del proceso migratorio, en la novela analizada. En la perspectiva de viabilizar el cumplimiento del segundo objetivo específico, además de la relectura de la novela elegida, se revisó, asimismo, las obras que clarifiquen los rasgos identitarios del sujeto migrante, para, en un tercer momento, buscar las citas más pertinentes y efectuar el análisis crítico de los principales rasgos identitarios que singularizan al sujeto migrante representado en la obra investigada.

Para la búsqueda y recuperación de la información requerida, en los dos tipos de fuentes antes citadas, se acudió a las bibliotecas de las universidades públicas y privadas de las ciudades de Quito, Guayaquil, Cuenca y Loja, así como a los servicios bibliográficos que están disponibles en las bases de datos científicas a las que tiene suscripción la Universidad Nacional de Loja y a las que se puede acceder y recuperar, a través de los buscadores disponibles en la Internet.
1. Caracterización de la Migración Internacional en la Seducción de

\section{los Sudacas}

Con Ramírez y Ramírez (2005) se sostiene que si bien en la década de los setenta hay logros en términos de crecimiento económico, de los salarios reales y de la calidad y extensión de los servicios estatales, la década de los ochenta es regresiva. "La devaluación de la moneda y la persistencia de la inflación tienen impactos devastadores en el ingreso de la población que se empobrece a lo largo de la década y ve frustradas las expectativas de mejores días (...). El incremento de la pobreza a lo largo de la década es, en efecto, evidente: según el Banco Mundial (1990), el porcentaje de la población ecuatoriana que en 1990 vivía bajo la línea de la pobreza fue del 65\%, (60,6\% según el SIISE) mientras que en 1970 abarcaba el 40\%"'.

Es que, como lo aseveran Acosta, López y Villamar (2006), entre los años de 1995 y el 2000, el Ecuador soportó la peor crisis de su historia reciente debido a la confluencia de varios factores causales. Entre los estructurales se pueden mencionar: la debilidad y fragilidad del mercado interno, causada por las enormes desigualdades en la distribución de la riqueza y la ausencia histórica de una política de desarrollo "desde adentro"; la presencia de sistemas de producción atrasados; la persistencia de un esquema administrativo bicentralista, que promueve la concentración de la riqueza en las dos principales ciudades del país: Guayaquil y Quito; escasos encadenamientos de producción y consumo, así como la reducida vinculación de la agricultura con la industria y de las actividades de exportación con el resto de la economía; la elevada propensión a importar tanto maquinarias, equipos y materias primas, como bienes de consumo, consecuencia de la histórica dependencia externa, tanto tecnológica como cultural; la falta de controles y normas sobre un aparato financiero corrupto e ineficiente; $y$, el mal manejo administrativo del Estado y una gran cantidad de ineficiencias acumuladas a través de la historia ${ }^{6}$.

${ }^{5}$ Ramírez Gallegos, Franklin y Ramírez, Jacques Paul. (2005). La estampida migratoria ecuatoriana. Crisis, redes transnacionales y repertorios de acción migratoria. 2 ed. Quito: Centro de Investigaciones CIUDAD. P. 41.

${ }^{6}$ Acosta, Alberto, López, Susana y Villamar, David. (2006). La migración en el Ecuador: oportunidades y amenazas. Quito: Centro Andino de Estudios Internacionales / Universidad Andina Simón Bolívar. Pp. 44-48. 
De entre los factores coyunturales que contribuyeron al desencadenamiento de crisis del Ecuador se pueden mencionar: de orden natural como la crisis eléctrica de 1995-1996, como consecuencia de un período de sequía que desencadenó el estancamiento de la economía ecuatoriana; la erupción del Volcán Tungurahua que forzó la evacuación de miles de personas de la ciudad de Baños y colapsó las actividades agrícolas y turísticas del sector; el fenómeno de El Niño, que debilitó la producción agrícola y pesquera, perjudicando a los sectores productivos sobre todo de la costa, en más de dos mil millones de dólares; de orden económico: como el incremento de la deuda externa cuyo monto per cápita, en el año 2000, llegó a 1375 dólares, la caída de los precios del petróleo, la desestabilización financiera internacional, el colapso bancario a consecuencia de la irresponsable utilización de los dineros de los depositantes en préstamos vinculados, sin ninguna garantía, a familiares y amigos de los banqueros corruptos, que originó el salvataje y la consecuente salida masiva de capitales, el ajuste económico de orden neoliberal, como la macro devaluación, la pérdida de empleo y los bajos salarios; de orden político, como la corrupción gubernamental; de orden cultural, porque los vecinos habían viajado, enviaban remesas y ellos también querían mejorar el nivel de vida y, de orden internacional, como el conflicto con el Perú de 1995.

Según la SENPLADES (2009), la crisis llegó a su punto máximo en marzo de 1999, cuando se decretó un feriado bancario y el congelamiento de los depósitos de los ahorristas. El Banco Central, por su parte, continuó su política de intensa emisión monetaria para evitar el desmoronamiento del sistema financiero. El aparato estatal se constituyó, así, en el eje de la recuperación de los sectores financieros quebrados?.

En lo político, el momento de mayor crisis se inicia con el levantamiento del pueblo, que en febrero de 1997, exigió la destitución de Abdalá Bucaram, elegido seis meses antes, debido a los escándalos de corrupción y al crecimiento acelerado de los niveles de pobreza.

7 Ecuador. Secretaría Nacional de Planificación del Desarrollo (SENPLADES). (2009).Plan Nacional para el Buen Vivir 2009 - 2013: Construyendo un estado nacional plurinacional e intercultural, Quito: SENPLADES. P. 64.
Al depuesto presidente lo sucedió, en calidad de "Interino", el entonces presidente del Congreso Nacional, Dr. Fabián Alarcón Rivera, quien entregó el poder al presidente electo, en agosto de 1998, Dr. Jamil Mahuad Witt, quien fue derrocado de sus funciones a los 18 meses de Gobierno, el 21 de enero del año 2000, y se posesiona al vicepresidente Dr. Gustavo Noboa Bejarano, que concluyó el mandato y entregó el poder al presidente electo, Coronel Lucio Gutiérrez Borbúa, quien gobernó dos años y tres meses, siendo reemplazado, en abril de 2005, por el vicepresidente Dr. Alfredo Palacio González, quien el 15 de enero de 2007 entregó el mando al Eco. Rafael Correa Delgado.

Ante panorama tan desolador, la mayoría de la población ecuatoriana dejó de creer en el Estado para remediar sus problemas, y volvió sus ojos hacia la emigración, que se convirtió en estrategia familiar y una válvula de escape para evitar una explosión mayor de la crisis. Pues, como dicen Acosta y otros: "La dureza de la crisis degeneró en una pérdida de fe en el futuro del país, y esto transformó a la emigración en una estrategia familiar generalizada de supervivencia. Así, la expectativa de los proyectos individuales y colectivos de los ecuatorianos se reorientaron hacia el exterior"8.

Contribuye, asimismo, al incremento de la emigración internacional, factores de tipo psicológico y cultural, como es el de mantener una posición relativa dentro de la comunidad y el "el mito del emigrante triunfador, que nace de la creencia de que el emigrante automáticamente encuentra trabajo en el exterior, accediendo a condiciones laborales ampliamente superiores a las domésticas. Supone, además, que el proceso de socialización, adaptación e integración del emigrante es inmediato" 9 .

Este mito se ve reforzado por el hecho de que aunque el emigrante se choque con una realidad totalmente diferente a la imaginada, es raro que acepte y divulgue públicamente los problemas por los que atraviesa.

${ }^{8}$ Acosta, Alberto y otros. (2006).Op. Cit. P. 60. ${ }^{9}$ Acosta, Alberto y otros. (2006). Op. Cit. P. 63. 
En tan complejas circunstancias se inició un proceso inédito de emigración internacional, cuya magnitud y velocidad no tienen precedentes en la historia del Ecuador; puesto que, según varias estimaciones “desde 2000 a 2004, más de un millón de ecuatorianos habrían salido del país; hay cálculos que superan las cifras mencionadas para los dos períodos descritos, pues establecen que el número de ecuatorianos y ecuatorianas en el exterior puede bordear los 3 millones"

Adicionalmente, analizada en clave sociológica, la actual ciudad y provincia de Loja, desde cuando tenemos información documental, siempre se ha caracterizado por constituir un espacio geográfico emisor de migrantes, hacia otras latitudes del país y el extranjero, de manera especial hacia la Costa, la Amazonía y las grandes ciudades (Quito y Guayaquil). Por las modificaciones de la economía global y las reformas en la legislación migratoria de los países receptores, en los años finales del siglo pasado y primeros del presente, Loja volvió a ser pionera en la provisión de migrantes, principalmente a España, Italia y otros estados nacionales del Hemisferio Norte.

Por estas razones, de acuerdo a lo que expresan Ramalhosa F. y Minkel W., en su folleto Características de la migración en la provincia de Loja, "se ha estimado que 150.000 lojanos dejaron la provincia durante un periodo de veinte años", entre 1962 y 1982. Sin embargo, esta cifra queda un tanto corta, cuando los mismos censos del INEC informan que la migración de lojanos dentro del país ha sido de 287.970 .

Según los autores citados, el flujo se dio primero de áreas rurales y ciudades secundarias hacia la capital provincial u otras regiones naturales o ciudades del Ecuador, y posteriormente con destino hacia otros países. En efecto, al analizar las tendencias migratorias en el Ecuador, se puede constatar, que hacia 1990 más del $33 \%$ de la población lojana había dejado su hogar¹.

\footnotetext{
${ }^{10}$ Acosta, Alberto y otros. (2006). Op. Cit. Pp. 43-44.

${ }^{11}$ Ramalhosa. Francisca; Minkel, C.W. (2001). Características de la migración en la provincia de Loja. Quito, Centro Panamericano de Estudios e Investigaciones Geográficas (CEPEIGE).P5.
}

En el caso de la emigración lojana, a las causas estructurales y económicas, hay que agregar las culturales, que se han ido forjando con el correr de los tiempos como la filosofía del desarraigo, con la que el lojano se "aferra a su querencia tolerando años agrícolas malos, crisis económica y malos gobiernos pero, al mismo tiempo, con el don de dejar lo que más quiere si está convencido de que debe marcharse" ${ }^{\prime 2}$. Incluso el Dr. Félix Paladines sostiene que, en el lojano "el ansia de caminar mundos, de despertar frente a nuevos paisajes, como que está escrita en la sangre de la gente de esta provincia. Es su tatuaje que se llevará pero en el alma”. Más adelante reafirma esta idea, al decir que el lojano siempre tuvo un corazón abierto a la aventura, a ver lo que hay más allá, aun a costa de arriesgar su seguridad y tranquilidad. Su felicidad no es estar en el mismo sitio sino conocer, ver mundo, ver la vida, arriesgarse. Por ello "al hombre de Loja lo encontramos siempre con las botas de siete leguas, siempre en una actitud trashumante, siempre como el río: yéndose y renovándose" ${ }^{13}$.

Con base en esta fundamentación teórica, en La seducción de los sudacas, al analizar las causas por las cuales se produjo la masiva emigración de los lojanos a España se las atribuyen a las pésimas administraciones gubernamentales del Ecuador, agudizadas por una crisis política y de gobernabilidad que parecían no tener fin: “[... ] con Abdalá Bucaram y Jamil Mahuad, los presidentes más birrias del planeta. [...] Culpó igualmente al jetón inepto de Lucio Gutiérrez, otro muérgano que tiene al Ecuador en la joda. Eso dice Radio Pueblo Nuevo." (Carrión, 2010: 143).

En lo atinente al viaje, una historia que describe la ruta migratoria es la referida a "El Vengador", un migrante ecuatoriano que nace en la actual provincia de Santo Domingo de los Tsáchilas y, luego, se traslada a vivir en la ciudad de Guayaquil; desde donde, con el apoyo de los coyoteros, se dirige hacia los Estados Unidos de Norteamérica, en una verdadera odisea que lo lleva por Colombia, Panamá, Guatemala y México hasta llegar a Estados Unidos de Norteamérica.

\footnotetext{
${ }^{12}$ Guerrero Carrión, Trotsky. (2003). Espejismo y realidad de la emigración lojana. Loja, Universidad Nacional de Loja. P. 104.

13 Paladines Paladines, Félix. (2000). Identidad y raíces. Loja: Casa de la Cultura Ecuatoriana, Núcleo Provincial de Loja. Pp. 123-124.
} 
Se radica en Nueva York y allí, por las malas influencias del entorno de amigos a los que frecuentaba y la necesidad de sobrevivir se convierte en delincuente, para más tarde integrarse a una banda de ladrones de joyas, que tienen como sus principales víctimas a los judíos.

Como consecuencia de esas fechorías, es privado de la libertad e ingresado a la cárcel Las Tumbas, en donde permanece por algún tiempo hasta cuando logra salir en libertad y decide cambiar de lugar de residencia a Madrid, en donde dice llegar en calidad de justiciero y vengador: "A rescatar el oro de Atahualpa y el oro, la plata y las piedras preciosas que, durante más de trescientos años, le shorearon a América (... ) Porque solo tres cosas los llevaron a América: matar hombres, violar mujeres y hartarse de oro." (Carrión, 2010: 541 - 541).

La llegada a España de un migrante lojano, por causas económicas es un acontecimiento que no reviste ninguna importancia, tal como se evidencia en la historia de Hernán, un abogado que decide emigrar, a trabajar en lo que sea, porque lo que gana en Loja no le alcanza; este migrante es recibido por tres amigos en Pamplona, quienes al saludarlo le dan la bienvenida con términos que ya son bastante decidores de lo que le espera: "Me calan el enojo y, para componerlo, bienvenido al infierno, Hernancito. Bienvenido a la tierra de ETA, del jamón serrano y las chavalas majas. Se burlan de mi pinta de futre de saco y corbata en pleno invierno, me preguntan si no siento frío y yo no." (Carrión, 2010: 341).

El asentamiento resulta, asimismo, muy complicado por cuanto la mayoría de migrantes ecuatorianos a lo que van a España es a trabajar en lo que sea, ganar dinero y regresar lo antes posible al lugar de origen; puesto que, al partir del país ellos no piensan en quedarse definitivamente fuera de él; además las condiciones de vida en España, en pisos hacinados, son muy difíciles. En estas estrecheces, lo más conflictivo se advierte en la utilización de los espacios físicos, que son de uso común: sala, comedor, cocina, baño, lavandería: “De noche los quince inquilinos se amontonan en la sala y en todas partes, y no sé cómo caben en los tres dormitorios y en el suelo. Unos huelen a cerveza, otros a tabaco, otros a vómito." (Carrión, 2010: 132).
Por supuesto que en el proceso migratorio analizado tienen mucho que ver las cadenas y redes migratorias, que se han ido constituyendo a lo largo de los años de migración lojana a España; por ejemplo, la decisión de viajar de Lycy no la toma por cuenta propia sino por las constantes insinuaciones e invitaciones de su amiga Rudy, que se había anticipado en la emigración: "La voz de una de ellas me recuerda a Rudy en el teléfono. Ven, Lucy, ven. No seas necia. En Madrid te forras, maja. (...) Me llamaba cada semana y como somos vecinas, su hermana o su mamá sacaba la cabeza de la puerta y Lucyyy, te llama Rudy, Luuucy." (Carrión, 2010: 130).

Una de las características de la actual migración internacional, que está presente en la novela analizada es el cambio de destino migratorio, desde Estados Unidos de Norteamérica hacia España como los lugares de mayor preferencia, en virtud de que en la nación ibérica se produce una radical transformación, al pasar de ser un Estado emisor de migrantes a convertirse en receptor. Hecho que se explica por cuanto, la transición española hacia un régimen democrático supuso una apertura al exterior, mediante la internacionalización de su economía, en un sistema cada vez más globalizado. La fuerte expansión económica y la no menos importante transformación política trajeron consigo profundos y rápidos cambios socioeconómicos. En palabras de Mora (2010), el mercado de trabajo se fue reestructurando y comenzó a producirse una creciente demanda laboral inmigrante, en nichos laborales que ahora eran rechazados por la población autóctona, con mayor formación y mayor nivel de renta que las generaciones anteriores ${ }^{14}$.

Además, en España había trabajo no calificado disponible y, aunque no se ganase tanto como en Estados Unidos de Norteamérica, el salario seguía siendo dos o tres veces superior al de Ecuador. Por otra parte, en opinión de Mora (2011), estaba el hecho de compartir la misma lengua ${ }^{15}$.

\footnotetext{
${ }^{14}$ Mora Umaña, Andrea Melissa. (2010). "El estudio de la inmigración desde la teoría de dinámica de tropas: el caso particular de los inmigrantes ecuatorianos en España", en Ciencias Económicas 28-No. 2.P. 388.

${ }^{15}$ Mora, Albert. (2011). [Entrevista respecto de la migración de ecuatorianos a España], en Revista Electrónica Spondylus, de la Universidad Andina Simón Bolívar, Sede Ecuador.
} 
Además, en el 2001, el gobierno español ratificó convenios bilaterales con Ecuador que simplificaban los trámites para la obtención de los visados de entrada y que reducían el precio del transporte aéreo.

Otra característica de la "estampida migratoria" ecuatoriana hacia España es la feminización del fenómeno migratorio, situación que se produce tanto por la apertura que se ha ido generando en el Ecuador, a favor de la equidad de género, como por el ambiente de la capital española, que no es nada hospitalario para los inmigrantes, sobre todo para los hombres: "Peor, porque aquí las mujeres tienen oportunidades; los hombres, no. Salvo en la mierda. Porque Madrid no te espera, tronca. Te rechaza o te destruye como un pulpo gigantesco. Ya sabes, Doly." (Carrión, 2010: 273).

Respecto de las ocupaciones de los ecuatorianos migrantes, como lo afirman Palazuelos y Palazuelos (2009), es necesario recalcar que, al igual que el resto de los inmigrantes no comunitarios, los ecuatorianos en España, aunque tengan estudios y títulos universitarios, solo obtienen empleo en unas pocas actividades, preferentemente del sector secundario de la economía: construcción, servicio doméstico y cuidados personales (ancianos, niños, enfermos), agricultura, hostelería (bares, restaurantes, etc.), correspondiendo siempre a las categorías inferiores en la escala jerárquica de distribución de los puestos de trabajo ${ }^{16}$.

No de otra forma se puede explicar el hecho de que en La seducción de los sudacas, "El Mangosta” se constituye en el ejemplo del inmigrante ecuatoriano que una vez terminados sus estudios universitarios se traslada a España a trabajar en condición de obrero no calificado: "Había venido a Madrid porque, al terminar la universidad, no había hallado en el Ecuador un solo trabajo en condiciones. Uno solo. Dieciséis años de estudio y sacrificio de su madre y de él para nada." (C. Carrión, 2010: 726); otro ejemplo es el de un odontólogo profesional, que desempeñaba su labor, como cualquier dentista empírico y en condiciones de artesano.

${ }^{16}$ Cfr. Palazuelos Manso, Antonio y Palazuelos, Diego. (2009). "Participación electoral y posicionamiento político de los inmigrantes ecuatorianos en la Comunidad de Madrid", en Participación política de los inmigrantes latinoamericanos en la Comunidad de Madrid. Madrid: Trama. P. 12.
En casos extremos y por la necesidad de sobrevivir, algunas jóvenes inmigrantes caen en la prostitución, directa o velada. Hecho relatado por Hernán, un abogado lojano inmigrante, que vive de fomentar o consentir la prostitución de su pareja, aunque él se arrepiente en lo más profundo de su ser: "Yo, en cambio, vivo de Doly. Soy un parásito, una garrapata, una tenia de cien metros, aunque no quiera saber nada de su pasta. Todo porque este oficio de cabrón me caga vivo y, en lo gilipollas que soy, pienso que lo mejor es buscar un camello, el que sea, como una salvación.” (C. Carrión, 2010: 413).

Aupados por el endurecimiento de la legislación española, expedida con la intencionalidad de controlar la migración “ilegal”, procedente de África y Sudamérica, los malos tratos y los sentimientos xenófobos de ciertos españoles, en contra de los inmigrantes ecuatorianos sin papeles, también están a la orden del día: “basura importada a bajo precio, maldita la hora en que Colón descubrió América, tenéis podrido vuestro país y venís a podrir el nuestro." (Carrión, 2010: 70). A decir de las migrantes que más experiencias negativas tienen respecto de las patronas: “Todas son así, jodidísimas, de verdad, todas. Agravios para arriba y para abajo; no se libran de ellos ni los hijos ni el marido.” (Carrión, 2010: 187).

\section{Rasgos Identitarios del Sujeto Migrante en la Seducción de los Sudacas}

Una de las principales características del lojano migrante en España, a diferencia de los habitantes nativos de ese Estado, se refiere a la cosmovisión y racionalidad comunitaria andina, por cuya práctica cultural y vivencia en el país de origen se advierte una inconformidad con la vida de los ancianos españoles, a los que tienen que cuidar; puesto que sus vidas tampoco son de júbilo y felicidad, como corresponde a una persona que ha entregado su vida labrando el futuro de la familia y la prosperidad de un Estado, sino que más bien está signada por el abandono, el desamor, la soledad y el maltrato al que se ven sometidos, incluso por sus propios hijos: "Ese hombre la llenó de hijos que desaparecieron salvo la más desamorada de todos, y se murió. Así que quedó igual o peor que antes hasta que María Luisa la trajo a Madrid. Solo para encontrarse con la vejez y la soledad." (Carrión, 2010: 152). 
En lo atinente a la creencia religiosa, en La seducción de los sudacaslos migrantes ecuatorianos ponen de manifiesto la influencia cultural de la religión católica cristiana y de su libro sagrado La Biblia, motivo por el cual ellos mismos se comparan con los del éxodo que dirigió el patriarca Moisés: "Somos los tíos del Éxodo, sentencia. Otros judíos. Pero no los inconformes de la Biblia. Ellos importunaban a Moisés día y noche." (Carrión, 2010: 440). Los inmigrantes, en sus conversaciones, creen que están viviendo el peor de los movimientos poblacionales: “Es el éxodo más cruel del planeta. (... ) Los judíos tuvieron a Moisés. Él tenía un palo mágico del que, tuin, salían mares rojos partidos en dos, agua, tablas de la ley, maná. Todo." (Carrión, 2010: 593).

La crítica del sistema educativo ecuatoriano y principalmente del nivel universitario, en La seducción de los sudacas, se lo hace a través de las historias de los sujetos migrantes, las cuales cuestionan la actividad académica de las universidades ecuatorianas, por ofertar carreras de formación profesional, de espaldas a las verdaderas necesidades del desarrollo del Ecuador, a consecuencia de lo cual entre los migrantes hay una gran cantidad de profesionales que van a trabajar en actividades para las cuales no se requiere ninguna cualificación laboral: "Y, como si no lo supiera, que Madrid está empedrado de graduados universitarios en trabajos así. Entonces imagino que los senderos del parque del Retiro no son sino la prolongación de los pasillos de las universidades del Ecuador." (Carrión, 2010: 649).

En razón de lo anterior, los estudios realizados en las universidades ecuatorianas tienen poca importancia o ningún valor, porque al término de los mismos no se encuentra ningún trabajo dentro del campo profesional, para el que se ha formado y se tiene que emigrar a realizar los trabajos que los españoles no quieren realizar: "Había venido a Madrid porque, al terminar la universidad, no había hallado en el Ecuador un solo trabajo en condiciones. Uno solo. Dieciséis años de estudio y sacrificio de su madre y de ella para nada." (Carrión, 2010: 726).
Otra de las características identitarias más sobresalientes del sujeto migrante lojano en España es la memoria, la cual según el italiano Alessandro Portelli (2002) debe entendérsela no como archivo del pasado, sino como el proceso que transforma los acontecimientos del pasado en materiales del presente, reelaborándolos continuamente; motivo por el cual la memoria sirve a los migrantes para reconstruir y adaptar su cultura y vida en el nuevo lugar de residencia o de tránsito.

En este sentido se podría decir que la memoria, individual o colectiva, al igual que la identidad y la cultura, es un proceso en permanente construcción, reconstrucción, cambio y transformación ${ }^{17}$.

Muy vinculado con este razonamiento, en los migrantes lojanos, en palabras de Conde (2004), una forma de mantener viva la memoria de su tierra natal es fomentar la organización de colonias para mantener tradiciones, socializar, revivir recuerdos entre migrantes y familiares $\mathrm{y}$, a través de ellas, promover actividades culturales, artísticas, musicales y literarias ${ }^{18}$.

En La seducción de los sudacas, los recuerdos acompañan a sol y sombra a quienes los llevan dentro de sí, es imposible liberarse de ellos: "Porque siempre va con uno lo que se ama. También lo que se odia, joder." (Carrión, 2010: 448).

No obstante, como es obvio que suceda, los buenos recuerdos de su tierra de origen, de un personaje protagónico, cuando era un artista que se presentaba en distintos escenarios de la provincia de Loja y el país, afloran a la mente de José Luis: “Recordó también las presentaciones artísticas de sus buenos tiempos (...) Lo mejor, sin embargo, era al final del concierto: las chicas coreaban su nombre, le pedían otra, lo esperaban en la puerta del local y se le iban encima como un terremoto por un autógrafo o un beso" (Carrión, 2010: 18).

${ }_{17}$ Portelli, Alessandro. (2002)."Memoria e identidad. Una reflexión desde la Italia postfascista”, en Jelin, Elizabeth y Victoria Langland (Compiladoras). Monumentos, memoriales y marcas territoriales. Cap. 8. Siglo Veintiuno: Memorias de la represión. España.Pp.165 y ss.

${ }^{18}$ Conde Salinas, Ángel. (2004).Identidad y transmisión cultural del migrante lojano: en el contexto de la ciudad de Santo Domingo de los Colorados. Loja: Casa de la Cultura de la Cultura Ecuatoriana Benjamín Carrión, Núcleo Provincial de Loja. P. 96. 
Muy vinculado a lo anterior, el amor a la tierra nativa, la nostalgia y los recuerdos constituyen otros de los rasgos identitarios del migrante lojano en España. Como dice Paladines (2000): “Cuando está lejos, vive con los recuerdos de la tierra, del hogar, de los amigos. Esos cálidos recuerdos forman parte de su ser. El lojano que se va es un nostálgico definitivo", y más adelante reafirma: "el lojano que está lejos siempre será un lojano ausente, siempre será un nostálgico incurable”" .

En La seducción de los sudacas, como ha dicho un estudioso del fenómeno migratorio, el aquí y ahora frente el allá y ayer lleva al inmigrante a idealizar el país de origen, a resaltar todas las cualidades que tenía en comparación con España; surge el desencanto por la Tierra Prometida y nace el sentimiento de Paraíso Perdido ${ }^{20}$. Siempre buscan un pretexto para reunirse, jugar, tomar, comer y, sobre todo, recordar al Ecuador: "Sin embargo, no es eso a lo que vienen aquí, sino a recordar el Ecuador, a llorar por él, como si haciéndolo en montón lloraran mejor que uno a uno." (Carrión, 2010: 543). Por supuesto que, en este complejo proceso, como dice el ya citado Cornejo Polar (1994), el sujeto migrante se instala en dos universos, de alguna forma antagónicos entre sí por sus valencias: el ayer y el allá, de un lado, y el hoy y aquí, de otro, aunque ambas posiciones estén inevitablemente teñidas la una por la otra en permanente pero cambiante fluctuación. De esta suerte el migrante habla desde dos o más locus y (...) duplica (o multiplica) la índole misma de su condición de sujeto ${ }^{21}$.

Consecuentemente, el sentimiento de desarraigo, en La seducción de los sudacas, de similar forma a lo que le sucedió a Ulises del poema épico de Homero y a todos quienes han abandonado su lugar de origen para luego pretender retornar, la imposibilidad de que los migrantes retornen a su patria es cierta: "Ningún emigrante regresa vivo a su patria, aunque regrese, sentencia.

\footnotetext{
${ }^{19}$ Paladines Paladines, Félix. (2000).Op. Cit. P. 123.

${ }^{20}$ Las Heras Mosteiro, J, Otero Puime, A., Gallardo Pino, C. (2008).El proceso migratorio y su repercusión en la salud. Voces de ecuatorianos en Madrid. 4p. ${ }^{21}$ Cornejo Polar, Antonio. (1994).Escribir en el aire: ensayos sobre la heterogeneidad socio-cultural, Lima: Horizonte. Pp. 277-278.
}

Ese es su destino, por eso él va a Barajas a ver salir los aviones, para hacerse la ilusión de regresar." (Carrión, 2010: 703). La migración cambia hasta la raíz del sujeto migrante: "Ya no soy el que fui. Nadie es el que ha sido cuando es un emigrante.” (Carrión, 2010: 299).

Razón por la cual la migración lleva a la paradoja, que más parece una maldición, por la cual el migrante no se encuentra tranquilo en ninguno de los dos lugares, ni en el de partida (Loja-Ecuador) ni en el de llegada (Madrid-España), si está en el uno quisiera estar en el otro y viceversa, ambivalencia que se pone de manifiesto en La seducción de los sudacas, cuando un migrante retorna al Ecuador y le va mal en el negocio instalado y advierte que no hay otra opción que no sea regresar a Madrid, los recuerdos de la capital española le hacen ver a su Loja natal como un pueblucho que nada tiene que ver con la gran metrópoli europea que ha conocido: “Caminaba por la Diez de Agosto, la 18 de Noviembre, la Sucre; comparaba esas calles con Princesa, Alcalá, Gran Vía y se reía. Joder, este pueblucho." (C. Carrión, 2010: 115).

En estas condiciones de precariedad laboral, los inmigrantes ecuatorianos van perdiendo la autoestima y la dignidad humana; por ello, no faltan los Ilamados chamberos que estaban tras la basura de los habitantes de la capital española, en aquellos barrios ricos, en donde encontraban los muebles que no podían comprar para amoblar los pisos que compartían y en esa humillante actividad tenían que disputarse la basura que los españoles arrojaban, con agresivos ciudadanos migrantes de otras nacionalidades: “Aparte de los ecuatorianos, había dos clases de saqueadores clásicos de un contenedor de basura suculento. Los gitanos de Vacía Madrid, que llevaban furgonetas y hormigueros de niños; de modo que, en un abrir y cerrar de ojos, barrían hasta con lo más inservible." (Carrión, 2010: 240).

Por supuesto que están plenamente conscientes de la degradación humana a que los ha llevado la migración: “Además, si yo soy gay y tú puta, eso es lo que somos tú y yo. Mejor dicho lo que ha hecho de nosotros la bendita migración." (Carrión, 2010: 253). 
Lo duro de la vida, dicen los propios migrantes, les va haciendo perder la autoestima hasta que la persona se deja abusar sin mayores protestas, los cosifica, los vuelve meros objetos: "Lo que ocurre, tronca, es que aquí, por la razón que sea, uno empieza a perder defensas, a dejarse abusar como un gil. A envilecerse. A pudrirse en vida, si esto es vida, claro, y sin que tú te des cuenta ni nada, no te digo." (Carrión, 2010: 256).

Las complejas problemáticas sociales y psíquicas por las que atraviesan a diario, el "olvido" del motivo del viaje de Ecuador a España hace que la vida pierda sentido y se embarque sin rumbo cierto en el tren subterráneo: "Cuando por fin llego y hallo un sitio, siento que me gustaría quedarme aquí horas de horas, días enteros, meses y años, sin llegar a ningún sitio, solo dando vueltas, una tras otra sin destino. Como en un círculo del infierno, en un laberinto." (Carrión, 2010: 457). Incluso, el sentido de falta de posesión es total y la comparación con lo que se sentía en el país de origen resulta insoportable: "En el Ecuador las calles de nadie son mías; aquí, en cambio, nada es mío. Nada. Ni el aire que respiro." (Carrión, 2010: 457).

Y entre las pérdidas están, también, la identidad cultural; puesto que no faltan las ecuatorianas que al poco tiempo de llegar a España aparentan ser conciudadanas de ese país y para ello utilizan la vestimenta y forma de hablar de las españolas: “Las tres tenían los sentidos pendientes del lucimiento de sus trajes, de su conversación, de fingirse españolas." (Carrión, 2010: 62).

Sin embargo de lo expresado, el migrante lojano se singulariza, también, por su carácter performativo, del que nos habla Raúl Bueno, práctica de vida que se evidencia en La seducción de los sudacas; puesto que, pese a todas las adversidades, para algunos migrantes dignos herederos de los lojanos y sabedores que nada es fácil ni gratuito, pero tampoco imposible, se dice que nada debe arredrarnos porque: "los mejores hombres siempre vuelven a empezar; no solo después de una catástrofe, sino cada día, cada hora." (Carrión, 2010: 699).

\section{Conclusiones}

En relación a la estampida migratoria de lojanos hacia España, a fines del Siglo XX y principios del XXI, en La seducción de los sudacas se describe, analiza y problematiza determinados aspectos vinculados a este complejo proceso social, desde las causas estructurales y coyunturales, principales y coadyuvantes; la salida, comenzando por los preparativos hasta la concreción; el viaje, por las distintas rutas migratorias que se hayan elegido; la llegada al lugar de destino; y, el asentamiento, el cual se puede facilitar o complicar dependiendo de los contactos que se tengan. En la novela analizada se explicitan, asimismo, algunas características de la actual migración internacional de los ecuatorianos: cadenas y redes migratorias; cambio de destino migratorio desde Estados Unidos de Norteamérica a España; feminización del proceso migratorio; ocupaciones de los migrantes ecuatorianos en el sector secundario de la economía española; malos tratos a los inmigrantes "sin papeles", por parte de algunos españoles xenófobos.

Los rasgos identitarios que singularizan al sujeto migrante representado en La seducción de los sudacas son la cosmovisión y la racionalidad comunitaria andina; la creencia religiosa católica; la crítica al sistema educativo de nivel superior; la memoria; el amor a la tierra nativa, la nostalgia y los recuerdos; el sentimiento de desarraigo; la paradoja de no estar conformes ni en el lugar de destino ni en el de origen; la paulatina pérdida del autoestima y la dignidad humana; y, el carácter performativo. Concluyéndose que hay una representación del proceso migratorio y del sujeto migrante muy cercana a la realidad y a los estudios sociológicos de la problemática analizada. Obviamente que los rasgos identitarios mencionados ameritan nuevos estudios, toda vez que funcionan como mecanismos de autoafirmación y de continua construcción y reconstrucción de la identidad del sujeto migrante proveniente de Loja, en lo individual y colectivo, en un permanente movimiento que, como el viento de los páramos andinos, las olas del mar o el pensamiento humano, no cesará nunca jamás. 


\section{Agradecimientos}

Gracias al PhD Rómulo Chávez Valdivieso, Director General de Investigaciones de la Universidad Nacional de Loja, por gestionar la aprobación del Proyecto de Investigación: La representación del fenómeno migratorio y del sujeto migrante en la narrativa ecuatoriana; por organizar, conjuntamente con la Dra. Cecilia Ruiz Toledo, el Seminario Taller: El artículo científico y la importancia de su publicación; y, por haber responsabilizado la conducción académica del evento al PhD Roldán Torres Gutiérrez y al PhD Nikolai Aguirre Mendoza; quienes, como docentes universitarios, han demostrado “arte, ciencia y sobre todo paciencia”, para garantizar la elaboración y presentación de artículos publicables.

\section{Referencias Bibliográficas}

Acosta, Alberto, López, Susana y Villamar, David (2006), La migración en el Ecuador: oportunidades y amenazas. Quito: Centro Andino de Estudios Internacionales / Universidad Andina Simón Bolívar. 269p.

Alvear, Stalin (2012).Trashumantes en busca de otra vida. Quito: Libresa. 253p.

Carrión, Carlos (2012).La seducción de los sudacas. Loja: Inédito. 824p.

Carrión Márquez, Mauricio. (s.f.).El sudaca mojado. Machala: Gobierno Provincial Autónomo de El Oro. 256p.

Conde Salinas, Ángel (2004).Identidad y transmisión cultural del migrante lojano: en el contexto de la ciudad de Santo Domingo de los Colorados. Loja: Casa de la Cultura de la Cultura Ecuatoriana “Benjamín Carrión”, Núcleo Provincial de Loja. 133p.

Cornejo Polar, Antonio (1994).Escribir en el aire: ensayos sobre la heterogeneidad socio-cultural. Lima: Horizonte.

Cuesta y Cuesta, Alfonso (2005).Los hijos, Edición preparada con estudio introductorio, cronología y notas por Jorge Dávila
Vázquez, Quito: Libresa. (Colección Antares N 176). 418p.

Ecuador. Secretaría Nacional de Planificación del Desarrollo (2009). Plan Nacional para el Buen Vivir 2009 - 2013: Construyendo un estado nacional plurinacional e intercultural. Quito: SENPLADES. 120p.

Galarza Dávila, Galo (2009), La Dama es una trampa, 3 Ed. Quito, Eskeletra. 218p.

Guerrero Trotsky Carrión (2003). Espejismo y realidad de la emigración Iojana. Loja, Universidad Nacional de Loja. 224p.

Las Heras Mosteiro, J.; A. Otero Puime, C. Gallardo Pino (2008).El proceso migratorio y su repercusión en la salud. Voces de ecuatorianos en Madrid.11p.

Martínez, Luis Alfredo (2005).A la Costa, Edición preparada con estudio introductorio, cronología y notas por Diego Araujo Sánchez, Quito: Libresa, (Colección Antares N² 2). 263p.

Mera, Juan León (2003).Cumandá o un drama entre salvajes, Quito: Casa de la Cultura Ecuatoriana “Benjamín Carrión”, Colección Media Luna $\mathrm{N}^{\circ} 7.215 \mathrm{p}$.

Merino Pérez, Gonzalo (2004).El Inmigrante. Guayaquil, Imprenta Magos. 181p.

Mora, Albert (2011). [Entrevista respecto de la migración de ecuatorianos a España], en Revista Electrónica Spondylus, de la Universidad Andina Simón Bolívar, Sede Ecuador.

Mora Umaña, Andrea Melissa (2010). “El estudio de la inmigración desde la teoría de dinámica de tropas: el caso particular de los inmigrantes ecuatorianos en España", en Ciencias Económicas 28-No. 2, 2010, p. 369-390.

Ortiz Crespo, Gonzalo. (2009). Los hijos de Daisy. Quito: Alfaguara. 398p.

Paladines Paladines, Félix (2000).Identidad y raíces. Loja: Casa de la Cultura Ecuatoriana, Núcleo Provincial de Loja. 264p.

Pareja Diezcanseco, Alfredo (2003).El muelle, Quito: Libresa (Crónica de sueños). 241p. 
Portelli, Alessandro (2002)."Memoria e identidad. Una reflexión desde la Italia postfascista”, en Jelin, Elizabeth y Victoria Langland (Compiladoras). Monumentos, memoriales y marcas territoriales. Cap. 8. Siglo Veintiuno: Memorias de la represión, España.P.165-190.

Ramalhosa. Francisca; Minkel, C.W. (2001). Características de la migración en la provincia de Loja. Quito, Centro Panamericano de Estudios e Investigaciones Geográficas (CEPEIGE). 25p.

Ramírez Gallegos, Franklin y Jacques Paul Ramírez (2005).La estampida migratoria ecuatoriana. Crisis, redes transnacionales y repertorios de acción migratoria, 2 ed. Quito: Centro de Investigaciones CIUDAD. 191p.

Rojas, Ángel Felicísimo (1985).El éxodo de Yangana. Quito: El Conejo. 36op.

Salazar Estrada, Yovany (2004).El pensamiento liberal y socialista en la obra de Ángel Felicísimo Rojas. Tesis de Magíster en Estudios de la Cultura, Mención: Literatura Hispanoamericana, presentada a la Universidad Andina Simón Bolívar, Sede Ecuador. Quito.89p.

Salazar Estrada, Yovany (2011).La migración en las novelas El éxodo de Yangana de Ángel Felicísimo Rojas y La seducción de los sudacas de Carlos Carrión Figueroa. Tesis de Magíster en Filosofía en un mundo global, presentada a la Universidad del País Vasco, San Sebastián. 98 p.

Salazar Estrada, Yovany (2013).La migración en la novelística lojana. Loja: Editorial "Gustavo Serrano Masache" de la Casa de la Cultura Ecuatoriana “Benjamín Carrión”, Núcleo de Loja. 212p.

Valdano Morejón, Juan (2006).La memoria y los adioses. Quito: Grupo Editorial Norma. 135p. 